\title{
Empreendedorismo para negócios digitais
}

DOI: 10.47224/revista master.v6i11.108

\author{
Danilo Faria de Moura \\ Emanuel Soares Ponciano \\ Izabella de Oliveira Costa \\ Juarez Monteiro Junior \\ Lays Yanes da Silva Coelho \\ Liliane Larissa Celestino \\ Ronaldo Jacinto Dias Junior \\ e-mail:danilofmoura@yahoo.com.br
}

\section{Resumo}

O empreendedorismo no Brasil se tem fortalecido cada vez mais, e o meio virtual vem se tornando uma nova tendência, oferecendo recursos para todo tipo de negócio. Esse artigo tem como objetivo principal a investigar sobre a relevância do empreendedorismo para os negócios digitais. Para a estruturação da pesquisa foi utilizada a Metodologia da Problematização com o Arco de Maguerez e foi vivenciada tendo como marco norteador a temática: o empreendedorismo no mundo virtual. O embasamento teórico teve aporte da pesquisa bibliográfica, sendo selecionados livros e artigos que convergem com a temática. Conclui-se que para a promoção do empreendedorismo, o primeiro passo, e mais importante, é levar o conhecimento sobre as diversas ferramentas disponíveis no mundo digital para os empreendedores, ainda desconhecidos por muitos deles.

Palavras-chave: Empreendedorismo; Marketing Digital; e-commerce.

\begin{abstract}
Entrepreneurship in Brazil has become increasingly stronger, and therefore the virtual environment has become a replacement trend, offering resources for all types of companies. the most objective of this text is to research the relevance of entrepreneurship for digital businesses. To structure the research, the Methodology of Problematization with the Arc of Maguerez was used, and it had been administered having as a guiding framework the theme: entrepreneurship within the virtual world. The theoretical foundation was supported by bibliographic research, with the choice of books and articles that converge with the theme. We conclude that, for the promotion of entrepreneurship, the primary and most vital step is to bring knowledge about the varied tools available within the digital world to entrepreneurs, still unknown to several of them.
\end{abstract}

Keywords: $\quad$ Entrepreneurship; Digital Marketing; e-commerce.

\section{INTRODUÇÃO}

Para Dornelas (2008, p. 14) “o empreendedorismo não se refere apenas à criação de novos negócios, é possível ser empreendedor dentro de empresas existentes, comportando-se de forma diferente, inovando e colaborando para o crescimento e sucesso da corporação." O autor ainda ressalta que esse é o papel que deve ser exercido pelo executivo moderno, procurando agir de forma empreendedora, assumindo riscos calculados, identificando oportunidades de negócios para a corporação, sendo criativo e um exímio trabalhador em equipe.

O presente artigo é resultante de atividades orientadas desenvolvidas no Curso de Administração. A estruturação da pesquisa se deu por meio da Metodologia da Problematização com o Arco de Maguerez e foi vivenciada tendo como marco norteador a temática: o empreendedorismo no mundo virtual. O embasamento teórico teve aporte da pesquisa bibliográfica, sendo 
selecionados livros e artigos que convergem com a temática.

O objetivo geral é investigar sobre a relevância do empreendedorismo para os negócios digitais. Compreendem-se como objetivo específico compreender a relação entre a mudança de comportamentos sociais e aumento dos negócios por meios digitais, principalmente provenientes dos avanços tecnológicos.

O empreendedorismo no Brasil tem se fortalecido cada vez mais, e o meio virtual vem se tornando uma nova tendência, oferecendo recursos para todo tipo de negócio, desse modo, permitindo que os profissionais em geral guiem seu negócio investindo pouco e obtendo rápidos retornos.

A era da informação é o período que começou na década de 1990, e suas principais características são as mudanças rápidas, turbulentas e inesperadas, os recursos tecnológicos como a Internet, transformaram o mundo num ambiente global, onde as interações ocorrem de modo simplificado, ou seja, um processo que poderia demorar para ser realizado já que demanda informações de outros países, com a Internet pode ser resolvido em questão de minutos. (DALFOVO et al. 2018, p. 199)

Compreende-se, assim, que o avanço da internet facilitou o surgimento de novas empresas no mercado, pois agora não é necessariamente um condicionante maior investir em uma estrutura física para iniciar um negócio. Com a ajuda de ferramentas online muitos empreendedores digitais gerenciam suas tarefas, fazem a venda de produtos ou serviços, e obtém a captação de clientes, utilizando poucos ou nenhum funcionário, minimizando assim os custos como salários entre outras despesas.

De acordo com informações publicadas pelo site ecommerce Brasil, Fernandes (2019) apresenta que o faturamento do E-commerce brasileiro cresceu 22,7\% em 2019, faturando R\$ 75,1 bilhões. Diante esse fato, evidencia-se que o marketing digital é um o potencializador para o aumento das chances de expansão da empresa em diversos lugares e a divulgação de sua marca, além dos vários benefícios que possui um empreendedor online.
Bom Ângelo (2003, p. 25) ressalta que "o empreendedorismo é a criação de valor por pessoas e organizações trabalhando juntas para implementar uma ideia por meio da aplicação de criatividade, capacidade de transformar e o desejo de tomar aquilo que comumente se chamaria de risco." Com as pessoas mais conectadas em plataformas virtuais, para agregar valor às pessoas se faz cada vez mais necessário migrar os modelos de negócios para essa nova realidade, o que exige gerenciamento de riscos, criatividade e transformação.

Justifica-se esse artigo pela necessidade imediata de adaptação das empresas, principalmente as mais tradicionais, de se colocarem de forma mista ou direta nas redes virtuais para manutenção e expansão de seus negócios. É mister destacar que muitas dessas empresas são geridas por pessoas mais conservadoras e com baixa afinidade com os recursos tecnológicos, podendo apresentar resistências às novas possibilidades apresentadas por esse novo mundo econômico, motivo pelo qual se reforça a importância dessa temática para o contexto social.

Algumas instituições locais incentivam o desenvolvimento da economia por meio de eventos e treinamentos específicos para empresas e empreendedores, como o Sebrae, que, em parceria com instituições das cidades em que atua implementa polos de discussão e fomento ao empreendedorismo. Os envolvidos nesses polos, empresários e entes sociais engajados com a economia local, promovem reuniões e eventos para estimular o empreendedorismo e inovação, além de eventos como jornadas de engajamento específicos.

Frente a essas sinalizações evidencia-se a falta de envolvimento dos comerciantes locais, principalmente os de empresas de pequeno porte, nas plataformas de vendas on-line, além da ausência de gerenciamento do Marketing Digital de seus negócios, sendo essa a problemática a ser explorada por esse artigo.

\section{COMPREENSÃO DA REALIDADE}

Para Dolabela (2006) a inovação tecnológica é o grande impulsionador econômico desde fins do século XX. Observou-se nas empresas locais da cidade de Araguari-MG que a abordagem do 
empreendedorismo virtual ainda não é uma realidade para os pequenos negócios. A utilização da internet e seus correlatos para a divulgação de suas empresas não é devidamente explorada, acarretando a limitação de conquistar novos cliente e aumento de vendas de seus produtos.

Conforme destacam Hisrich, Peters e Shepherd (2014, p. 52) "um grande desafio ao empreendedor, que pode levá-lo à ação ou inibi-lo, é a segurança para tomar decisão em um ambiente de incerteza." E diante dessa colocação justifica-se de aprofundamento na temática em questão, uma vez que os investimentos para utilização $e$ posicionamento das redes virtuais em prol da expansão dos negócios não envolvem, atualmente, grandes riscos.

Fernandes (2019) apresenta informações vinculadas em reportagem pelo site e-commerce Brasil colocam em destaque que o poder de aquisição do consumidor não sofreu variações significativas entre 2018 e 2019, porém o aumento no volume de compras on-line aumentou em 22,5\%. Esses aspectos comprovam a necessidade de transição dos negócios do presencial para o digital, ou pelo menos que sejam adotados modelos mistos pelos empreendedores.

Criatividade diante das oportunidades, disposição para assumir riscos, perseverança, otimismo e senso de independência são posturas relativamente comuns aos empreendedores. Para identificar oportunidades de atuação nas plataformas digitais os empreendedores devem se capacitar, conhecer sobre as possibilidades e vantagens de atuação. (MAXIMIANO, 2012)

Por meio da problemática é possível prover soluções que contribuam efetivamente para o empreendedorismo local e para a formação prática nos Cursos de Administração aos discentes dedicados à essa causa.

Para Maximiano (2012) o empreendedor assume as responsabilidades do negócio; sua ação é intencional e busca ampliar as suas redes de relacionamento. Essa rede de relacionamento também pode ser estendida para a visão de clientes como parceiros para o negócio, como promotores dos produtos comercializados, podendo atingir maior abrangência através dos canais digitais.

Mediante as questões observadas e destacadas notam-se fatores de grande relevância a serem considerados nesse contexto, tais fatores relacionados à fatores imediatos e fatores condicionantes maiores.

Fatores imediatos:

- Falta de conhecimento sobre ferramentas digitais;

- Estagnação nas vendas por baixo alcance de clientes;

- Falta de praticidade no atendimento aos clientes.

Fatores condicionantes maiores:

- Baixo investimento na capacitação de empreendedores;

- Pouca divulgação das possibilidades de vendas em plataformas digitais nos canais de maior acesso pelos empreendedores mais tradicionais;

- Baixa afinidade com as tecnologias por parte dos empreendedores com negócios estáveis.

Por meio de reflexões acerca dos fatores imediatos e os condicionantes maiores, associados ao problema, destacou-se, para o presente artigo, alguns aspectos essenciais ou pontos-chave:

- Aprimoramento de habilidades tecnológicas ligadas ao negócio;

- Marketing digital para micro e pequenas empresas;

- Empreendedorismo digital.

\section{MARKETING DIGITAL E EMPREENDEDORISMO}

Para validação dos aspectos detectados por meio da observação da realidade buscou-se a fundamentação teórica que propiciasse a confrontação e um maior embasamento a respeito dos pontos-chave levantados e que, consequentemente, pudesse conduzir às hipóteses de solução para o problema eleito.

Segundo definição de Barreto (1998, p. 191) "empreendedorismo é a habilidade de se conceber e estabelecer algo partindo de muito pouco ou 
quase nada." Partindo dessa premissa alguns novos negócios estão sendo constituídos com estruturas físicas rudimentares e se projetando nas redes virtuais em busca de clientes que atualmente são consumidores de empresas tradicionais. Esses clientes contam com comodidades de receber em casa suas compras e os novos empreendedores de fazer baixos investimentos para abrir seus negócios.

Segundo vinculado no site Conrado Adolpho, autor do livro "Os 8 Ps do Marketing digital" e promotor de discussões acerca da temática:

Em 2014, um terço dos diretores entrevistados em uma pesquisa da AdWeek já afirmava que o digital seria o destino de $75 \%$ do orçamento de marketing das empresas nos próximos 5 anos. Em 2018, de fato, $R \$ 16,54$ bilhões foram aplicados em publicidade online apenas no Brasil, segundo dados do Cenp (Conselho Executivo das Normas-Padrão), e a expectativa ainda é de crescimento. (ADOLFO, 2019, documento online)

O marketing digital está em alta, não apenas no Brasil, mas no mundo todo. Grande parte dos clientes potenciais de diversos segmentos são alcançados através da internet, por meio de várias redes sociais que estão disponíveis de forma gratuita e facilmente acessíveis. E em um cenário de crise, é o marketing digital que tem contribuído para que muitos empreendedores continuem atendendo seus clientes e evitando que suas atividades precisem ser encerradas.

\section{FALTA DE CONHECIMENTO SOBRE FERRAMENTAS DIGITAIS}

De acordo Cavanelli (2019, documento online) em matéria vinculada pelo site Época Negócios "o Brasil é o quarto país com maior presença online, mas seus conhecimentos online não são considerados sofisticados." $\mathrm{Na}$ pesquisa inédita realizada em colaboração pelo Google em parceria com a McKinsey, Digital Skills Index - Índice de Habilidades Digitais, o país registrou um índice médio de $3 \mathrm{em}$ uma escala que vai até 5 . A pesquisa ainda aponta que "apesar de $70 \%$ da população usar redes sociais e passar em média mais de 9 horas por dia conectada, faltam habilidades no uso de ferramentas de criação e programação, registrando o menor índice entre os países avaliados - apenas 1,8." (CAVANELLI, 2019, documento online)

Um apontamento de suma relevância sinalizado pela pesquisa confirma que "o investimento nessa área levaria ao um aumento de até R\$ 380 na renda mensal, equivalente a $40 \%$ do salário-mínimo, e injetaria até U\$ 70 bilhões no PIB brasileiro até 2025." (CAVANELLI, 2019, documento online)

Atualmente há diversas ferramentas digitais disponíveis para ajudar empreendedores de todas as áreas, e a cada dia novas tecnologias surgem para levar praticidade e maiores oportunidades para quem quer empreender e obter sucesso.

Existem ferramentas que ajudam na divulgação dos produtos e da marca, como redes sociais, sites, lojas online, ferramentas que ajudam a identificar o público que tem visitado as propagandas e que são potenciais clientes, há ferramentas para organização das finanças, estoques, entre outras. Essas ferramentas são muito úteis e facilitam o trabalho e organização do empreendimento.

Muitos empreendedores deixam de usufruir dos recursos disponíveis por essas ferramentas por falta de conhecimento, e isso é uma desvantagem, não só para o empreendedor, mas para os clientes também, que cada vez mais preferem um atendimento online que ofereça mais praticidade $\mathrm{e}$ comodidade.

Segundo dados do Ibope vinculados pelo Portal G1 (G1, 2019, documento online) mais da metade da população brasileira está conectada à internet e o Brasil país é o quinto mais conectado do mundo. Isso revela que que as pequenas empresas não estão mais limitadas apenas aos clientes que estão ao seu redor ou às antigas campanhas de marketing.

De acordo com uma cartilha desenvolvida pelo Sebrae (2019, documento online) com as principais ferramentas que uma pequena empresa precisa para fazer bons negócios na internet, hoje em dia as principais oportunidades das empresas estão online, e, agora, elas podem competir em tom de igualdade com outras maiores. Por outro lado, a internet tem muitas especificidades e exige dos empreendedores um novo modelo de relacionamento com os clientes, além de uma nova forma de agir no mercado.

Com essas inovações tecnológicas muitos empresários começaram, de maneira muita intensa, a expor o seu produto ou serviço em vários de sites, 
redes sociais, buscadores e reprodutores de conteúdos espalhados em diferentes links e acessados por diferentes perfis de pessoas. Isso traz muitos ganhos para os negócios, afinal, trata-se de uma chance de aumentar os resultados de visibilidade e comerciais, além de quebrar barreiras de acesso aos consumidores e diminuir os custos de divulgação.

Com isso, a disputa online pela atenção do cliente fica alta. Por isso, é essencial ter conhecimento sobre ferramentas digitais e planejar uma boa presença digital, para se colocar à frente da concorrência.

\section{ESTAGNAÇÃO NAS VENDAS POR BAIXO ALCANCE DE CLIENTES}

Para a empresa se manter competitiva no mercado e crescer progressivamente, é necessário investir na divulgação de seus produtos, buscando conhecer o perfil de seus clientes e os possíveis canais onde eles serão alcançados.

De acordo com a reportagem do site SCE Sistemas (2019, documento online), "as mídias sociais são um fenômeno mundial, o Facebook tem mais de 2,6 bilhões de usuário espalhados pelo mundo, 8 em cada 10 Brasileiros estão conectados nele." A reportagem ainda afirma que "o Instagram já tem mais de mais de 1 bilhão de usuários e o WhatsApp mais de 1,5 bilhões de usuários" (SCE SISTEMAS, 2019, documento online). Frente a esse cenário é importante salientar a relevância de se utilizar essas mídias para fomentar diversos negócios é fundamental.

Muitos empreendedores focam mais no produto a ser oferecido, e esquecem que para aumentar as vendas é necessário investir na divulgação, fidelizar os clientes já existentes, atrair novos clientes, fortalecer a imagem da empresa, e com isso as vendas ficam estagnadas.

O marketing digital é uma ótima ferramenta para alcançar um número significativo de clientes em um curto período, utilizar as redes sociais para divulgar os produtos e a imagem da empresa é a estratégia mais utilizada por empreendedores que buscam inovar e atrair a atenção dos clientes, alavancando as vendas e trazendo grandes oportunidades de crescimento.
Conforme destaca o presidente do Sebrae, Guilherme Afif Domingos em pesquisa divulgada pelo Sebrae (2016, documento online) "vender pela internet é uma tendência que não pode ser deixada de lado. O mundo virtual permite que os clientes conheçam e comprem os produtos de um pequeno negócio 24 horas por dia. Os donos de pequenos negócios já perceberam isso e têm marcado presença nas redes."

Em pesquisa feita pelo Sebrae (2016) também constatou que de 2013 a 2015 houve um aumento considerável no número de pessoas que resolveram vender produtos ou serviços pela internet. A pesquisa revela ainda que do total de e-commerce no país, $58 \%$ deles começaram suas atividades na rede de 2013. O levantamento também detectou que $53 \%$ das empresas que vendem on-line não possuem uma loja física e que uma em cada quatro empresas possui apenas um funcionário e 40\%, entre dois e quatro funcionários.

\section{BAIXO INVESTIMENTO NA CAPACITAÇÃO DE EMPREENDEDORES}

Alves (2017, p. 163) relata que "diante de uma economia cada vez mais sensível e do avanço da comunicação, da informação e da tecnologia o mercado tornou-se cada vez mais competitivo e as empresas estão se preocupando em se fortalecer e se diferenciar das demais."

A autora retrata que os clientes passam a contar com ferramentas de pesquisas por preços e qualidade para que tomem as melhores decisões frente as opções que possuem.

Devido às ferramentas de busca na internet os clientes podem consultar, em tempo real, os menores preços, tornando-os ainda mais exigentes devido à variedade de escolhas, e aumentando seu poder de barganha. Por essa razão, as empresas passaram a se readequar conforme a necessidade do cliente buscando estratégias para se diferenciar dos concorrentes e se manter no mercado. (ALVES, 2017, p. 163) 
A prática do empreendedorismo mostra-se cada vez mais frequente no Brasil. O número de brasileiros que abrem o próprio negócio é alto. Segundo pesquisa do Global Entrepeneurship Monitor - GEM, coordenada pela London Business School da Inglaterra e pelo Babson College dos Estados Unidos, em uma lista de 34 países, o Brasil está entre os sete que mais empreendem em criação de novas empresas.

O empreendedorismo no Brasil começou a tomar forma na década de 1990, quando entidades como Sebrae (Serviço Brasileiro de Apoio às Micro e Pequenas Empresas) e Softex (Sociedade Brasileira para Exportação de Software) foram criadas.

Entretanto, um estudo divulgado pelo Instituto Brasileiro de Geografia e Estatística - IBGE (2010) sinalizou que mais da metade das empresas brasileiras não sobrevive após os quatro primeiros anos.

Dentre as causas do fechamento destas empresas, destacam-se aquelas classificadas como de origem gerencial. Tais causas estão relacionadas à falta de planejamento na abertura do negócio, levando o empresário a não avaliar, de forma correta, fatores importantes para o sucesso ou fracasso do empreendimento, tais como o fluxo de caixa, a concorrência nas proximidades do ponto escolhido e o potencial dos consumidores, dentre outros fatores.

A capacitação por meio de cursos específicos destinados aos empreendedores, com métodos de ensino prático que remetem a realidade do mercado e das empresas, são de grande auxílio para quem deseja ou já possui uma Micro e Pequena Empresa MPE.

\section{HIPÓTESES DE SOLUÇÃO DO PROBLEMA}

A reflexão dos aspectos desenvolvidos durante a pesquisa realizada com base na literatura e através de artigos, livros e sites que vinculam conteúdos referentes a temática, possibilitou apresentar diversas alternativas que contribuem para a solução do problema estudado:

- Oferecer cursos online, e-books, palestras, reuniões, entre outros materiais didáticos, para que os empreendedores tenham o conhecimento necessário sobre as ferramentas digitais aplicadas aos seus negócios;

- Fazer pesquisas sobre quais canais mais se encaixam com o ramo de cada empresa especifica e fazer um bom planejamento para implantação destes canais de forma eficiente;

- Aderir às redes sociais para divulgação de produtos/serviços e aproximação com clientes, facilitando a comunicação entre cliente e empresa;

- Fazer dinâmicas e campanhas que incentivem os colaboradores a serem mais criativos e terem mais disposição para buscar novidades para que a empresa se mantenha sempre competitiva.

\section{APLICAÇÃO À REALIDADE}

A partir da análise das hipóteses de solução, de uma reflexão acerca dos fatores imediatos e das condicionantes maiores, bem como do contexto no qual se encontra o problema em questão, foi possível eleger algumas contribuições para a solução do problema apresentado, com o objetivo de intervir na realidade de modo a buscar melhorias e o sucesso dos empreendimentos. A aplicação real não se fez possível em virtude da pandemia da COVID-19, sendo apresentado aqui uma possibilidade para contribuir com esse cenário.

O primeiro passo é levar conhecimento sobre as diversas ferramentas disponíveis no mundo digital para os empreendedores, a partir de então eles estarão preparados para escolherem quais ferramentas mais se encaixam com o tipo de produto/serviço que a empresa oferece e o tipo de público que querem alcançar. Eles poderão usufruir das vantagens que essas ferramentas oferecem, alcançando grande número de clientes, tendo uma comunicação muito mais prática e clara, aumentando as vendas e fortalecendo a imagem da empresa.

Essa formação poderá ser realizada através de cursos, presenciais ou online, ou através de palestras e eventos mais constantes e específicos para esse público. Sabe-se que o Sebrae oferece cursos online e gratuitos disponíveis para os diversos 
empreendedores, independentemente da localidade ou segmento de atuação, porém a capacitação básica de manuseio de recursos digitais se faz necessário.

A partir dessa formação inicial é possível avançar no entendimento dos melhores canais e ferramentas para segmentos específicos. Assim todos são beneficiados, o consumidor que terá acesso a um leque maior de empresas e produtos, o empreendedor que terá maior alcance do seu negócio e a economia que será facilitada pelo marketing digital.

\section{CONSIDERAÇÕES FINAIS}

Os autores de referência e a observação da realidade nos possibilita inferir que ser empreendedor vai muito além de ter um negócio próprio, empreender é ter paixão pelo que faz, é assumir riscos calculados para obter crescimento, é buscar inovar em cada detalhe e se agarrar em todas as oportunidades que aparecem.

O mundo virtual oferece inúmeras ferramentas para auxiliar os empreendedores a ter um melhor desempenho nas atividades do dia a dia e, consequentemente, alcançar os objetivos da empresa.

Tendo como objetivo central investigar a importância do empreendedorismo para os negócios digitais, foi possível comprovar que é essencial que ambos caminhem sempre juntos, aumentando as possibilidades de crescimento e sucesso.

Nota-se que muitos empreendedores ainda não aproveitam as vantagens do mundo virtual, com isso acabam ficando às margens do mercado em que atuam, com seu potencial de vendas estagnado, pois o mundo virtual possibilita um alcance imensurável de clientes através de diversos canais, e a falta de utilização desses canais torna sua manutenção e crescimento muito limitados. Isso acontece, na maioria dos casos, por falta de conhecimento dessas ferramentas digitais. Pequenos empreendedores acreditam que seja muito complexo trabalhar utilizando a internet, e que pode exigir um investimento muito alto, e, assim, optam por utilizar ferramentas mais tradicionais.
Desta forma, chega-se à compreensão de que o primeiro passo para empreender de forma sustentável é levar conhecimento sobre as diversas ferramentas disponíveis no mundo digital para os empreendedores, a partir disso eles estarão preparados para escolherem quais ferramentas mais se encaixam com o tipo de produto/serviço que a empresa oferece e o tipo de público que querem alcançar.

\section{REFERÊNCIAS}

A Importância do Marketing Digital. SCE Sistemas, 2016. Disponível em:

https://www.scesistemas.com.br/noticiashome/importancia-do-marketingdigital\#: :text=As\%20m\%C3\%ADdias\%20sociais\%20 s\%C3\%A3o\%20um,1\%2C5\%20bilh\%C3\%B5es\%20de \%20usu\%C3\%A1rios. Acesso em: 02 de jun. de 2020.

ADOLFO, C. Conrado Adolfo, 2019. Por que investir em marketing digital? Descubra 7 motivos! Disponível em: https://www.conrado.com.br/porque-investir-em-marketing-digital/. Acesso em: 20 de jun. de 2020.

\section{BARRETO, L. P. Educação para o}

Empreendedorismo. Salvador: Escola de Administração de Empresa da Universidade Católica de Salvador, 1998, p. 189-197.

\section{BOM ANGELO, Eduardo. Empreendedor} corporativo: a nova postura de quem faz a diferença. Ed. Rio de Janeiro: Editora Elsevier, 2003.

Brasil é o quinto colocado em número de pessoas conectadas. G1, 2019. Disponível em:

https://gq.globo.com/Prazeres/Tecnologia/noticia/ 2019/06/brasil-e-o-quinto-colocado-em-numerode-pessoasconectadas.html\#: :text=0\%20pa\%C3\%ADs\%20\%C 3\%A9\%20superado\%20pela,voc\%C3\%AA\%20tamb \%C3\%A9m\%20tenha\%20mais\%20internautas.

Acesso em: 08 de jun. de 2020 .

CAVANELLI, E. Google: Apesar de conectado, falta conhecimento digital sofisticado ao brasileiro. Época Negócios, 2019. Disponível em: https://epocanegocios.globo.com/Tecnologia/notic ia/2019/03/google-apesar-de-conectado-falta- 
conhecimento-digital-sofisticado-ao-

brasileiro.html\#: :text=0\%20Brasil\%20\%C3\%A9\%2

0o\%20quarto,escala\%20que\%20vai\%20at\%C3\%A9

\%205. Acesso em: 12 de jun. de 2020.

Como pequenas empresas podem fazer bons negócios na internet. Sebrae Nacional, 2019.

Disponível em:

https://m.sebrae.com.br/sites/PortalSebrae/bis/fer ramentas-para-fazer-bons-negocios-nainternet,13b915bfd0b17410VgnVCM1000003b740 10aRCRD. Acesso em: 17 mai. 2020.

Como planejar a sua presença digital. Sebrae Nacional, 2019. Disponível em:

https://m.sebrae.com.br/sites/PortalSebrae/artigo s/como-planejar-a-sua-presencadigital,9cda25f0fe391710VgnVCM1000004c00210a RCRD. Acesso em: 17 mai. 2020.

DALFOVO, Oscar; DALFOVO, Michael Samir; MACHADO, Mirian Magnus. Inteligência competitiva: teoria e prática como inteligências nos negócios. Blumenau: Tambolin, 2018.

DORNELAS, José Carlos Assis. Empreendedorismo corporativo: como ser empreendedor, inovar e se diferenciar na sua empresa. 2. ed. Rio de Janeiro: Elsevier, 2008.

DOLABELA, Fernando. O segredo de Luísa, uma ideia, uma paixão e um plano de negócios: como nasce o empreendedor e se cria uma empresa. 14. ed. São Paulo: Cultura, 2006.

FERNANDES, Dinalva. E-commerce brasileiro cresce $\mathbf{2 2 , 7 \%}$ com faturamento de R\$ 75 bi em 2019.

Disponível em:

https://www.ecommercebrasil.com.br/noticias/ecommerce-brasileiro-cresce-2019-compreconfie/.

Acesso em: 28 abr. 2020.

HISRICH, R. D.; PETERS, M. P.; SHEPHERD, D. A. Empreendedorismo. 9. ed. Porto Alegre: AMGH, 2014.

Instituto Brasileiro de Geografia e Estatística IBGE. Estatísticas do Cadastro Central de Empresas. Brasília, 2010.

LAVADO, T. Uso da internet no Brasil cresce, e 70\% da população está conectada. G1, 2019. Disponível em: https://g1.globo.com/economia/tecnologia/noticia /2019/08/28/uso-da-internet-no-brasil-cresce-e70percent-da-populacao-esta-conectada.ghtml. Acesso em: 08 de jun. de 2020.

MAXIMIANO, A. C. A. Empreendedorismo. São Paulo: Pearson Prentice Hall, 2012.

Pequenos negócios dominam vendas na internet. Sebrae Nacional, 2016. Disponível em: http://www.agenciasebrae.com.br/sites/asn/uf/NA /pequenos-negocios-dominam-vendas-nainternet,35044e8a89c26510VgnVCM1000004c0021 OaRCRD. Acesso em: 16 mai. 2020.

MONITOR, Global Entrepreneurship. Empreendedorismo no Brasil: 2016. Curitiba: IBQP, p. 1-208, 2017.

ALVES, M. A importância do atendimento ao cliente em pequenas empresas - um estudo de caso. REGRAD - Revista Eletrônica de Graduação do UNIVEM - ISSN 1984-7866, [S.I.], v. 10, n. 01, p. 163 - 173, oct. 2017. ISSN 1984-7866. Disponível em:

https://revista.univem.edu.br/REGRAD/article/vie $\mathrm{w} / 2157$. Acesso em: 16 mai. 2020. 